\title{
Could fructan sources in strawberry matrix be more effective as a tool for improvement of bone structure than these compounds added to diet alone? - Study on osteopenic rat model
}

\author{
Kinga Topolska ${ }^{1, A, C-D, F \oplus}$, Radosław Piotr Radzki ${ }^{2, B, F \oplus}{ }^{\text {, Agnieszka Filipiak-Florkiewicz }}{ }^{1, C, F \oplus}$, \\ Marek Bieńko ${ }^{2, B, F}$, Adam Florkiewicz ${ }^{3, B, F} \oplus$, Ewa Cieślik ${ }^{1, E-F} \oplus$ \\ ${ }^{1}$ Department of Nutrition Technology and Consumption, Faculty of Food Technology, University of Agriculture, Kraków, \\ Poland \\ 2 Department of Animal Physiology, Faculty of Veterinary Medicine, University of Life Sciences, Lublin, Poland \\ ${ }^{3}$ Department of Food Analysis and Quality Assessment, Faculty of Food Technology, University of Agriculture, Kraków, \\ Poland
}

A - Research concept and design, B - Collection and/or assembly of data, C - Data analysis and interpretation, $D$ - Writing the article, E-Critical revision of the article, $F$ - Final approval of article

\begin{abstract}
Topolska K, Radzki RP, Filipiak-Florkiewicz A, Bieńko M, Florkiewicz A, Cieślik E. Could fructan sources in strawberry matrix be more effective as a tool for improvement of bone structure than these compounds added to diet alone? - Study on osteopenic rat model. Ann Agric Environ Med. 2020; 27(1): 19-28. doi: 10.26444/aaem/108656
\end{abstract}

\begin{abstract}
Ibstract
Introduction. Osteoporosis, a disease associated with ovarian hormone deficiency following menopause, is the most common cause of age-related bone loss. Although an optimal intake of $\mathrm{Ca}$ is vital - both bone accretion during growth and maintenance in adult life - a great percentage of the population consumes far below the recommended amounts of this mineral. On the other hand, there are evidences that fructans enhance not only Ca absorption, but bone calcium as well. Objective. In the knowledge that estrogen deficiency and insufficient $C a$ in the diet during postmenopause cause serious problems with resultant osteoporosis, the aim of this study is to assess the effects of a diet enriched in fructan-containing sources alone, or in the "strawberry matrix", on the structure of bone in OVX rats under calcium hypoalimentation.

Materials and method. Experimental animals were female Wistar rats, sham-operated or ovariectomized. The treatment with Ca-restricted diets also contained one of the sources of fructan (Jerusalem artichoke, yacon, Beneo Orafti Synergy1), in the amount providing $8 \%$ of fructans. Femur architecture of rats was assessed by tomography and Ca content by the AAS method.

Results. Ovariectomy led to a significant decrease in femoral Ca content, total mineral content and bone density of rats. This study shows that a diet containing inulin-type fructan (especially as a component of strawberry product) improved bone quality (i.e. increase in Ca content in femur, total density in middle part of bone, as well as decrease of endosteal circumference) in OVX rats under calcium hypoalimentation.

Conclusions. These findings suggest that a fructan-enriched diet could be potentially useful for postmenopausal osteoporosis. It is important to determine an optimal dietary level of fructan with the long-term goal of developing a dietary strategy in osteoporosis prevention.
\end{abstract}

\section{Key words}

ovarian hormone deficiency, calcium intake, fructans, bone

\section{INTRODUCTION}

Osteoporosis, a disease associated with deficiency of ovarian hormone following menopause, is undoubtedly the most common cause of age-related bone loss [1]. This disease is estimated to affect 200 million women worldwide, and by 2050 , the global incidence of hip fracture in women is projected to increase by $240 \%$, compared to rates in 1990 [2, 3]. A decline in ovarian production of estrogens at menopause often results in a rapid loss of trabecular microarchitecture, increased endocortical bone resorption, and increased cortical porosity; all these changes being

Address for correspondence: Kinga Topolska, Department of Nutrition Technology and Consumption, Faculty of Food Technology, University of Agriculture in Kraków, Poland

E-mail: kinga.topolska@urk.edu.pl

Received: 20.02.2019; accepted: 05.04.2019; first published: 25.04.2019 associated with an elevated risk for fracture, and culminating in the development of osteoporosis [4].

Bone requires an adequate consumption of $\mathrm{Ca}$; this mineral is necessary for both bone accretion during growth (to achieve an optimum peak bone mass) and maintenance in adult life (to suppress bone turnover) [5]. Although an optimal intake of this mineral is vital, a large percentage of the population consumes levels that are far below the recommended amounts. According to Kumssa et al. [6], 3.5 billion people are at risk of Ca deficiency because of inadequate dietary supply. The combination of calcium deficiency and oophorectomy enhances the overall loss of bone. Following oophorectomy, the calcium intake with diet required to remain in balance increases about 5 -fold [7]. Thus, estrogen deficiency and insufficient calcium in the diet in postmenopause can cause serious problems with resultant osteoporosis [1]. 
The ovariectomized (OVX) rat is an approved model for studying how the decline in endogenous estrogen production by the ovaries at menopause leads to postmenopausal osteoporosis. It is also useful to know how potential interventions can protect bone metabolism [4]. As the prevalence of osteoporosis is increasing, natural dietary components with the potential to help prevent this disease are considered [8].

Among the functional ingredients, inulin-type fructan plant carbohydrates, attract special attention because they have been linked to a number of health benefits. Inulintype fructans may contribute, in a significant way, to a wellbalanced diet by affecting several gastrointestinal functions (composition of microflora in the intestine, mucosal functions, endocrine activities, absorption of minerals) and even systemic ones (i.a. lipid homeostasis, immune functions), as well as by reducing the risk of some diseases [9]. It is also known that antioxidant-rich foods may represent one more strategy for slowing down bone loss and improving bone remodeling.

There are evidences that have identified a higher intake of fruit with decreased fracture risk [10]. Strawberry is the one of the most popular fruits because of its unique organoleptic attributes and the content of bioactive compounds (i.e. phenolic compounds, vitamin C) [11, 12]. A strawberry "matrix" (because of its composition and physicochemical properties) could therefore be a valuable environment for fructan action. Moreover, there are evidences that fructan in strawberry product are stable [13]. The last, but not the least reason for choosing such a product as strawberry sorbet was that many people like frozen fruit dessert and consume them quite often.

The presented study, a continuation of a wide range of research on biological verification of fructan action in different rat models, is aimed at evaluating the effect of a diet enriched in one of three fructan-containing sources on selected bone quality parameters in ovariectomized rats with insufficient calcium intake.

\section{MATERIALS AND METHOD}

Research materials. Jerusalem artichoke (Helianthus tuberosus L.) var. Albik (pulp from tubers), yacon (Smallanthus sonchifoulis) - root powder (Oxapampa, Peru - EverTrust, UK) and Beneo Orafti Synergy 1 (Belgium) were used as the research materials - alone or as components of strawberry (Fragaria $\times$ ananassa Duchesne) var. Senga Sengana (Oerlemans Foods, Poland) products, according to the recipe and preparation by Topolska et al. [13].

Animals, experimental design and procedures. Experimental animals were 12-weeks old female Wistar rats, with the mean body weight of $269.4 \pm 31.4 \mathrm{~g}$. They were kept in an animal house, in a controlled environment $(12 / 12 \mathrm{~h}$ day:night ratio at $22 \pm 2{ }^{\circ} \mathrm{C}$ and $55 \pm 2 \%$ humidity), in Tecniplast plastic cages (Eurostandard Type IV 1354G; 3 rats per cage) with ad libitum access to deionized water and diet. After an acclimatization period, the rats were randomly submitted to sham-operation ( $\mathrm{SHO}$ - when ovaries were isolated from the approach in the medial line and replaced intact), or bilateral ovariectomy (OVX). OVX animals had ovaries removed bilaterally from the approach in the medial line, and special care was taken to prevent accidental reimplantation of ovarian tissue. Observed uterine atrophy (during dissection) evidenced that ovariectomy was performed correctly.

After convalescence (4 days), animals were randomly assigned to groups (8 rats in each group). The first 3 groups were for validation; two of them were sham-operated rats fed modified AIN-93M diet [14] with recommended (SHO-RC; Ca 5,000 mg/kg diet) or lowered (SHO-LC; Ca deficiency $40 \%$, i.e. $3,000 \pm 0.1 \mathrm{mg} / \mathrm{kg} \mathrm{diet)} \mathrm{dietary} \mathrm{calcium} \mathrm{level,} \mathrm{and}$ the last group consisted of the ovariectomized animals fed a diet with lowered Ca dose (OVX-LC; Ca deficiency - 40\%, i.e. $3,000 \pm 0.1 \mathrm{mg} / \mathrm{kg}$ diet $)$.

The subsequent 6 treatment groups were animals fed Carestricted, modified AIN-93M diets, but enriched in one of selected fructan sources, i.e. Jerusalem artichoke (pulp), yacon (root powder) and the formulation Beneo Orafti Synergy 1 - each one added alone (OVX-LC-JA, OVX-LC-Y, OVX-LC-F) or with the strawberry product (OVX-LC-JAS, OVX-LC-YS, OVX-LC-FS). The fructan sources were added to the diet in amounts providing $8 \%$ of fructans. Jerusalem artichoke pulp, as well as all sorbets, were added to the diet after lyophilization (Christ Alpha 1-4 apparatus, Germany). The formulations of treatment diets (containing all fructan sources) were calculated to provide equal contents of calcium $(3,000 \pm 0.1 \mathrm{mg} / \mathrm{kg} \mathrm{diet})$ and fibre, (Suppl. Tab. 1).

During feeding, experimental SHO-RC animals received the diet ad libitum, while the other groups received the same amounts; the purpose being to avoid hypertrophy. The body weight of rats was monitored weekly. At the end of the experiment (after 8 weeks of feeding), rats were euthanized according to ethical guidelines.

Ethical standards. All applicable institutional and/or national guidelines for the care and use of animals were followed. The procedures were approved by the First Local Ethical Committee on Animal Testing at the Jagiellonian University in Kraków (no 119/2011).

Femora sampling and analyses. The hind legs of the rats were dissected. To prevent desiccation of the bone samples, the legs were frozen at $-80^{\circ} \mathrm{C}$, until measurements were taken. The femora were then dissected and separated with blade surgery, removing the tissue adhering to the bone.

The femoral Ca content was measured by the AAS method with flame atomization (ASA Varian AA240FS), according to PN-EN 15505:2009 [15]. At first, wet mineralization (maximum temperature set at $200^{\circ} \mathrm{C}$, mineralization time $40 \mathrm{~min}$ ) was performed using MarsXpress (CEM, USA), with $65 \%$ nitric acid (Suprapur ${ }^{\oplus}$ Merck, Germany). The accuracy of the method used was verified on the basis of certified reference material (NCS ZC73012-GSB-5). The method was validated and checked by internal quality control procedure [16] and inter-laboratory/proficiency tests.

The bones were scanned with peripheral Quantitative Computed Tomography (pQCT) XCT Research SA Plus system, with software version 6.2C (Stratec Medizintechnik $\mathrm{GmbH}$, Pforzheim, Germany). The scans were performed in the distal metaphysis ( $5 \mathrm{~mm}$ from distal end) for analysis of the trabecular bone tissue and also in the middle diaphysis (50\% of bone length) for analysis of the cortical bone tissue.

The following parameters were determined in the middle (M) and distal (D) parts of the femur: cortical thickness (D-CRT_THK, M-CRT_THK), cortical area (D-CRT_A, M-CRT_A), cortical density (D-CRT_DEN, M-CRT_DEN), 
Table 1. Experimental diets for female rats - composition and energy value

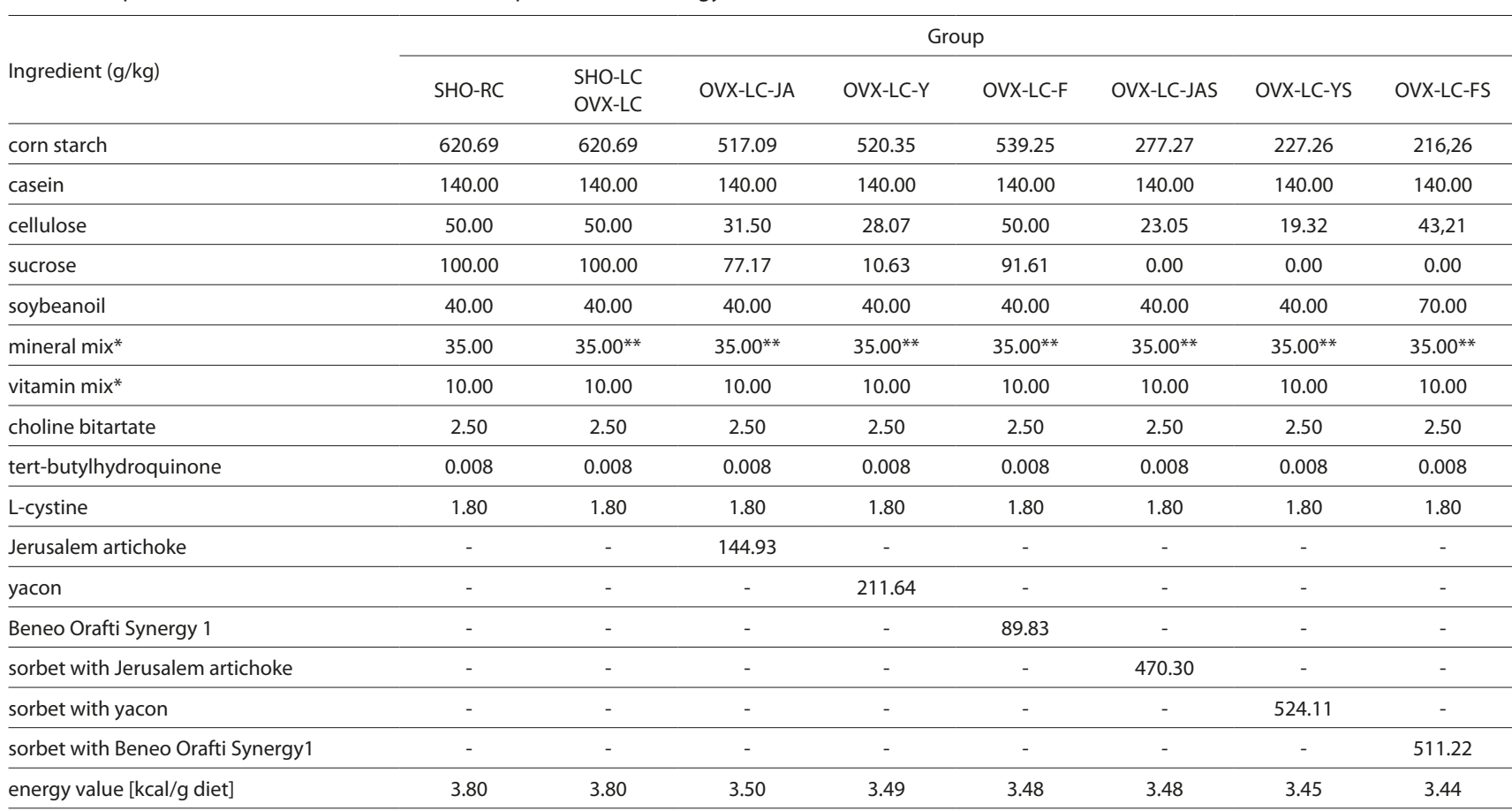

* mineral mix in RC group as well as vitamin mix (in all groups) were prepared according to Reeves et al.[14]

** in LC groups corn starch was placed in mineral mix instead of calcium

SHO-RC - diet with recommended calcium dose - Ca content: $5,000 \mathrm{mg} / \mathrm{kg}$ diet; LC - calcium deficient diets ( $60 \%$ recommended Ca dose - Ca content: $3,000 \pm 0.1 \mathrm{mg} / \mathrm{kg}$ diet), i.e. SHO-LC and OVX-LC: low-calcium diet, OVX-LC-JA: low-calcium diet enriched in Jerusalem artichoke, OVX-LC-Y: low-calcium diet enriched in yacon, OVX-LC-F: low-calcium diet enriched in Beneo Orafti Synergy 1, OVX-LC-JAS: low-calcium diet enriched in sorbet containing Jerusalem artichoke, OVX-LC-YS: low-calcium diet enriched in sorbet containing yacon, OVX-LC-FS: low-calcium diet enriched in sorbet containing Beneo Orafti Synergy 1

cortical content (D-CRT_CNT, M-CRT_CNT), trabecular area (D-TRAB_A, M-TRAB_A), total area D-TOT_A, M-TOT_A), trabecular density (D-TRAB_DEN, M-TRAB_ DEN), trabecular content (D-TRAB_CNT, M-TRAB_CNT), total density (D-TOT_DEN, M-TOT_DEN), total content (D-TOT_CNT, M- TOT_CNT), polar strain index (D-RPCM-W), as well as periosteal (D-PERI_C, M-PERI_C) and endosteal circumferences (D-ENDO_C,M-ENDO_C).

The cortical tissue was tested with a threshold of $0.900 \mathrm{~cm}^{-1}$ and cortical mode 2 . In turn, analyses of the trabecular bone were performed with a threshold of $0.450 \mathrm{~cm}^{-1}$, contour mode 2 , and a peel mode 20 . The initial scan was performed at a speed of $10 \mathrm{~mm} / \mathrm{s}$, and CT-scan $4 \mathrm{~m} / \mathrm{s}$. The pQCT system was calibrated with the use of hydroxyapatite containing a quality assurance phantom (pQCT QA-Phantom).

Statistical analysis. Data were presented as mean value \pm standard deviation (SD). All the calculations were performed with statistical software package Statistica 9.1 (StatSoft Inc., USA). Hypothesis about normal distribution (Shapiro-Wilk test) as well as homogeneity of variance (Levene'a test), was verified. Differences between SHO-RC and SHO-LC groups, as well as between SHO-LC and OVX-LC, were analyzed by Student's t-test. Differences between OVX-LC and other treatment groups were tested with the one-way analysis of variance (ANOVA) and post hoc Tukey's test as a correction for multiple comparisons. Differences were considered significant at $\mathrm{p} \leq 0.05$.

Principal Component Analysis (PCA) was also performed (statistical software package Statistica 9.1; StatSoft Inc., USA) to better illustrate the differences between experimental groups. There were three versions of PCA; the first included only groups of the validation model, the second - OVX groups fed low-calcium diets (without SHO groups), while the third - all groups (validation model as well as treatments groups).

\section{RESULTS}

Femoral calcium content and bone quality parameters in validation model. Feeding SHO rats with low-calcium diet did not change markedly ( $p>0.05)$ the level of this mineral in bone. (Suppl. Tab. 2). In turn, ovariectomy caused a significant reduction in femoral Ca content in female rats (SHO-LC vs. OVX-LC, -9.71\%).

To assess the femur architecture of female Wistar rats, peripheral Quantitative Computed Tomography was used. It was observed that consumption of the calcium-deficient diet by SHO rats negatively influenced D-ENDO_C (+7.21\%), while D-PERI_C was not significantly affected ( $\mathrm{p}>0.05)$. Moreover, ovariectomy caused enhancement of endosteal circumference $(+15.93 \%)$, compared with SHO-LC. Additionally, the D-PERI_C value was higher (+12.15\%) in OVX-LC vs. SHOLC. OVX rats had significantly lower D-TRAB_CNT and D-TRAB_DEN, compared to SHO-LC animals $(-48.83 \%$ and $-54.38 \%$, respectively). Calcium deficiency in SHO rats also caused a decrease in trabecular density by almost $5 \%$; however, this change was not statistically significant. The trabecular content parameter in these validation groups, mentioned above, remained similar $(\mathrm{p}>0.05)$. Total mineral content, as well as total bone density in the distal part of the femora, were dramatically decreased due to ovariectomy, from $14.88-11.94 \mathrm{mg} / \mathrm{mm}$ and $863.80-619.03 \mathrm{mg} / \mathrm{mm}^{3}$, respectively. The value of $\mathrm{D}-\mathrm{RP}-\mathrm{CM}-\mathrm{W}$ was also radically decreased in ovariectomized rats, compared to SHO-LC 
Table 1. Effects of fructan sources (raw materials) on bone calcium content and femoral architecture in ovariectomized rats

\begin{tabular}{|c|c|c|c|c|}
\hline \multirow{2}{*}{ Parameter (unit) } & \multirow{2}{*}{ OVX-LC } & \multicolumn{3}{|c|}{ Kind of fructan source } \\
\hline & & OVX-LC-JA & OVX-LC-Y & OVX-LC-F \\
\hline Femoral Ca (mg/g) & $192.75^{\mathrm{b}} \pm 9.34$ & $194.56^{\mathrm{b}} \pm 6.67$ & $208.96^{c} \pm 5.95$ & $184.30^{\mathrm{a}} \pm 6.06$ \\
\hline D-ENDO_C (mm) & $13.61 \pm 0.52$ & $12.60 \pm 0.99$ & $13.20 \pm 0.61$ & $12.80 \pm 0.90$ \\
\hline D-PERI_C (mm) & $15.55 \pm 0.50$ & $14.67 \pm 0.77$ & $15.10 \pm 0.62$ & $14.88 \pm 0.73$ \\
\hline D-TRAB_A $\left(\mathrm{mm}^{2}\right)$ & $8.66 \pm 0.57$ & $7.72 \pm 0.80$ & $8.17 \pm 0.68$ & $7.95 \pm 0.78$ \\
\hline D-TOT_A ( $\left.\mathrm{mm}^{2}\right)$ & $19.26 \pm 1.26$ & $17.16 \pm 1.79$ & $18.17 \pm 1.51$ & $17.67 \pm 1.73$ \\
\hline D-TRAB_DEN (mg/mm³) & $276.79 \pm 58.55$ & $314.04 \pm 56.20$ & $311.45 \pm 44.07$ & $291.18 \pm 46.62$ \\
\hline D-TRAB_CNT (mg/mm) & $2.41 \pm 0.60$ & $2.43 \pm 0.55$ & $2.56 \pm 0.53$ & $2.33 \pm 0.50$ \\
\hline D-TOT_DEN (mg/mm³) & $619.03 \pm 32.61$ & $663.21 \pm 52.76$ & $659.46 \pm 23.02$ & $651.48 \pm 36.45$ \\
\hline D-TOT_CNT (mg/mm) & $11.94 \pm 1.18$ & $11.34 \pm 1.12$ & $12.00 \pm 1.27$ & $11.49 \pm 1.14$ \\
\hline D-RP-CM-W $\left(\mathrm{mm}^{3}\right)$ & $7.01 \pm 0.74$ & $6.76 \pm 0.65$ & $7.09 \pm 1.04$ & $7.03 \pm 0.79$ \\
\hline M-ENDO_C (mm) & $6.75^{b} \pm 0.44$ & $6.21^{\mathrm{a}} \pm 0.28$ & $6.32^{\mathrm{a}} \pm 0.32$ & $6.31^{\mathrm{a}} \pm 0.17$ \\
\hline M-PERI_C (mm) & $10.77 \pm 0.42$ & $10.41 \pm 0.27$ & $10.47 \pm 0.34$ & $10.39 \pm 0.22$ \\
\hline M-CRT_THK (mm) & $0.64 \pm 0.0$ & $0.67 \pm 0.02$ & $0.66 \pm 0.04$ & $0.65 \pm 0.04$ \\
\hline M-CRT_A ( $\left.\mathrm{mm}^{2}\right)$ & $5.60 \pm 0.25$ & $5.56 \pm 0.27$ & $5.55 \pm 0.42$ & $5.42 \pm 0.39$ \\
\hline M-CRT_DEN (mg/mm³) & $1464.89 \pm 10.29$ & $1475.06 \pm 10.10$ & $1470.25 \pm 12.22$ & $1467.60 \pm 10.86$ \\
\hline M-CRT_CNT (mg/mm) & $8.20 \pm 0.34$ & $8.19 \pm 0.37$ & $8.17 \pm 0.61$ & $7.95 \pm 0.63$ \\
\hline M-TOT_A (mm²) & $8.87 \pm 0.28$ & $8.62 \pm 0.44$ & $8.74 \pm 0.57$ & $0.59 \pm 0.37$ \\
\hline M-TOT_DEN (mg/mm³) & $972.29^{\mathrm{a}} \pm 31.22$ & $1027.75^{b} \pm 25.82$ & $1011.44^{\mathrm{b}} \pm 35.99$ & $1009.25^{b} \pm 37.43$ \\
\hline M-TOT_CNT (mg/mm) & $8.96 \pm 0.42$ & $8.86 \pm 0.45$ & $8.83 \pm 0.58$ & $8.67 \pm 0.62$ \\
\hline
\end{tabular}

a, b- different letters mean significant differences among groups ( $\mathrm{p} \leq 0.05) \mathrm{OVX}$-LC: low-calcium diet, OVX-LC-JA: low-calcium diet enriched in Jerusalem artichoke, OVX- LC-Y: low-calcium diet enriched in yacon, OVX-LC-F: low-calcium diet enriched in Beneo Orafti Synergy 1, cortical thickness (D-CRT_THK, M-CRT_THK), cortical area (D-CRT_A, M-CRT_A), cortical density (D-CRT_DEN, M-CRT_DEN), cortical content (D-CRT_CNT, M-CRT_CNT), trabecular area (D-TRAB_A, M-TRAB_A), total area (D-TOT_A, M-TOT_A), trabecular density (D-TRAB_DEN, M-TRAB_DEN), trabecular content (D-TRAB_CNT, M-TRAB_CNT), total density (D-TOT_DEN, M-TOT_DEN), total content (D-TOT_CNT, M-TOT_CNT), polar strain index (D-RP-CM-W), as well as periosteal (D-PERI_C, M-PERI_C) and endosteal circumferences (D-ENDO_C, M-ENDO_C), where $D$ - means distal part of bone; $M$ - means middle part of bone.

Table 2. Effects of fructan-enriched strawberry products on bone calcium content and femoral architecture in ovariectomized rats

\begin{tabular}{|c|c|c|c|c|}
\hline \multirow{2}{*}{ PARAMETER (unit) } & \multirow{2}{*}{ OVX-LC } & \multicolumn{3}{|c|}{ Kind of sorbet } \\
\hline & & OVX-LC-JAS & OVX-LC-YS & OVX-LC-FS \\
\hline Femoral Ca $(\mathrm{mg} / \mathrm{g})$ & $192.75^{\mathrm{a}} \pm 9.34$ & $241.19^{\mathrm{b}} \pm 5.71$ & $203.58^{\mathrm{a}} \pm 4.26$ & $203.11^{a} \pm 1.21$ \\
\hline D-ENDO_C (mm) & $13.61^{b} \pm 0.52$ & $13.07^{b} \pm 0.48$ & $12.35^{\mathrm{a}} \pm 0.90$ & $13.18^{b} \pm 0.80$ \\
\hline D-PERI_C (mm) & $15.55^{\mathrm{b}} \pm 0.50$ & $15.15^{b} \pm 0.44$ & $14.56^{\mathrm{a}} \pm 0.72$ & $15.29^{b} \pm 0.85$ \\
\hline D-TRAB_A $\left(\mathrm{mm}^{2}\right)$ & $8.66^{b} \pm 0.57$ & $8.22^{b} \pm 0.47$ & $7.61^{\mathrm{a}} \pm 0.74$ & $8.40^{b} \pm 0.92$ \\
\hline D-TOT_A (mm²) & $19.26^{b} \pm 1.26$ & $18.28^{\mathrm{b}} \pm 1.05$ & $16.91^{\mathrm{a}} \pm 1.66$ & $18.66^{\mathrm{b}} \pm 2.04$ \\
\hline D-TRAB_DEN $\left(\mathrm{mg} / \mathrm{mm}^{3}\right)$ & $276.79 \pm 58.55$ & $293.69 \pm 38.36$ & $345.70 \pm 53.86$ & $304.38 \pm 69.87$ \\
\hline D-TRAB_CNT (mg/mm) & $2.41 \pm 0.60$ & $2.42 \pm 0.40$ & $2.65 \pm 0.61$ & $2.60 \pm 0.82$ \\
\hline D-TOT_DEN $\left(\mathrm{mg} / \mathrm{mm}^{3}\right)$ & $619.03^{\mathrm{a}} \pm 32.61$ & $647.74^{\mathrm{a}} \pm 27.25$ & $699.13^{b} \pm 31.68$ & $653.38^{\mathrm{a}} \pm 37.38$ \\
\hline D-TOT_CNT (mg/mm) & $11.94 \pm 1.18$ & $11.84 \pm 0.92$ & $11.81 \pm 1.13$ & $12.24 \pm 1.87$ \\
\hline D-RP-CM-W $\left(\mathrm{mm}^{3}\right)$ & $7.01 \pm 0.74$ & $7.40 \pm 0.95$ & $7.17 \pm 0.67$ & $7.51 \pm 1.17$ \\
\hline M-ENDO_C (mm) & $6.75^{\mathrm{b}} \pm 0.44$ & $6.32^{\mathrm{a}} \pm 0.30$ & $6.05^{\mathrm{a}} \pm 0.36$ & $6.27^{\mathrm{a}} \pm 0.39$ \\
\hline M-PERI_C (mm) & $10.77^{b} \pm 0.42$ & $10.50^{\mathrm{b}} \pm 0.30$ & $10.25^{\mathrm{a}} \pm 0.35$ & $10.64^{b} \pm 0.37$ \\
\hline M-CRT_THK (mm) & $0.64^{\mathrm{a}} \pm 0.0$ & $0.66^{\mathrm{ab}} \pm 0.03$ & $0.68^{b c} \pm 0.01$ & $0.69^{c} \pm 0.04$ \\
\hline M-CRT_A $\left(\mathrm{mm}^{2}\right)$ & $5.60 \pm 0.25$ & $5.51 \pm 0.29$ & $5.57 \pm 0.27$ & $5.77 \pm 0.47$ \\
\hline M-CRT_DEN (mg/mm³) & $1464.89 \pm 10.29$ & $1474.88 \pm 12.63$ & $1472.68 \pm 12.27$ & $1471.99 \pm 10.26$ \\
\hline M-CRT_CNT (mg/mm) & $8.20 \pm 0.34$ & $8.12 \pm 0.47$ & $8.20 \pm 0.39$ & $8.50 \pm 0.70$ \\
\hline M-TOT_A (mm²) & $8.87 \pm 0.28$ & $8.77 \pm 0.51$ & $8.37 \pm 0.58$ & $9.02 \pm 0.63$ \\
\hline M-TOT_DEN (mg/mm³) & $972.29^{\mathrm{a}} \pm 31.22$ & $1017.78^{b} \pm 33.44$ & $1032.03^{b} \pm 37.66$ & $1040.83^{b} \pm 42.88$ \\
\hline M-TOT_CNT (mg/mm) & $8.96 \pm 0.42$ & $8.93 \pm 0.53$ & $8.62 \pm 0.49$ & $9.37 \pm 0.57$ \\
\hline
\end{tabular}

$\mathrm{a}, \mathrm{b}$ - different letters mean significant differences among groups ( $\mathrm{p} \leq 0.05$ ) OVX-LC: low-calcium diet, OVX-LC-JAS: low-calcium diet enriched in sorbet containing Jerusalem artichoke, OVX-LC-YS: low-calcium diet enriched in sorbet containing yacon, OVX-LC-FS: low-calcium diet enriched in sorbet containing Beneo Orafti Synergy1, cortical thickness (D-CRT_THK, M-CRT_THK), cortical area (D-CRT_A, M-CRT_A), cortical density (D-CRT_DEN, M-CRT_DEN), cortical content (D-CRT_CNT, M-CRT_CNT), trabecular area (D-TRAB_A, M-TRAB_A), total area (D-TOT_A, M-TOT_A), trabecular (D-CRT_A, M-CRT_A), cortical density (D-CRT_DEN, M-CRT_DEN), cortical content (D-CRT_CNT, M-CRT_CNT), trabecular area (D-TRAB_A, M-TRAB_A), total area (D-TOT_A, M-TOT_A), trabecular
density (D-TRAB_DEN, M-TRAB_DEN), trabecular content (D-TRAB_CNT, M-TRAB_CNT), total density (D-TOT_DEN, M-TOT_DEN), total content (D-TOT_CNT, M- TOT_CNT), polar strain index (D-RPdensity (D-TRAB_DEN, M-TRAB_DEN), trabecular content (D-TRAB_CNT, M-TRAB_CNT), total density (D-TOT_DEN, M-TOT_DEN), total content (D-TOT_CNT, M-TOT_CNT), polar str
$\mathrm{CM}-\mathrm{W}$ ), as well as periosteal (D-PERI_CM-PERI_C) and endosteal circumferences (D-ENDO_C, M-ENDO_C), where D - means distal part of bone; $M-$ means middle part of bone. 
Table 2. Changes in the calcium content as well as tomographic parameters in validation groups

\begin{tabular}{|c|c|c|c|}
\hline \multirow[b]{2}{*}{$\begin{array}{l}\text { Parameter } \\
\text { (unit) }\end{array}$} & \multicolumn{3}{|c|}{ VALIDATION MODEL } \\
\hline & SHO-RC & SHO-LC & OVX-LC \\
\hline Femoral Ca (mg/g) & $208.6 \pm 6.22$ & $213.47^{b} \pm 7.98$ & $192.75^{\mathrm{a}} \pm 9.34$ \\
\hline D-ENDO_C (mm) & $10.95^{A} \pm 0.67$ & $11.74^{\mathrm{Ba}} \pm 0.74$ & $13.61^{b} \pm 0.52$ \\
\hline D-PERI_C (mm) & $14.70 \pm 0.40$ & $14.70^{\mathrm{a}} \pm 0.66$ & $15.55^{\mathrm{b}} \pm 0.50$ \\
\hline D-TRAB_A $\left(\mathrm{mm}^{2}\right)$ & $7.74 \pm 0.45$ & $7.75^{\mathrm{a}} \pm 0.70$ & $8.66^{b} \pm 0.57$ \\
\hline D-TOT_A (mm²) & $17.22 \pm 1.01$ & $17.23^{\mathrm{a}} \pm 1.57$ & $19.26^{\mathrm{b}} \pm 1.26$ \\
\hline D-TRAB_DEN $\left(\mathrm{mg} / \mathrm{mm}^{3}\right)$ & $632.13 \pm 47.19$ & $606.7^{b} \pm 31.5$ & $276.79^{\mathrm{a}} \pm 58.55$ \\
\hline D-TRAB_CNT (mg/mm) & $4.90 \pm 0.54$ & $4.71^{b} \pm 0.54$ & $2.41^{\mathrm{a}} \pm 0.60$ \\
\hline D-TOT_DEN & $895.46^{B} \pm 28.68$ & $863.80^{\mathrm{Ab}} \pm 27.96$ & $619.03^{\mathrm{a}} \pm 32.61$ \\
\hline D-TOT CNT & $15.41 \pm 0.90$ & $14.88^{b} \pm 1.36$ & $11.94^{\mathrm{a}} \pm 1.18$ \\
\hline D-RP-CM-W $\left(\mathrm{mm}^{3}\right)$ & $10.58^{B} \pm 0.95$ & $9.20^{\mathrm{Ab}} \pm 1.26$ & $7.01^{\mathrm{a}} \pm 0.74$ \\
\hline M-ENDO_C (mm) & $6.58^{B} \pm 0.35$ & $6.19^{\mathrm{Aa}} \pm 0.25$ & $6.75^{b} \pm 0.44$ \\
\hline M-PERI_C (mm) & $10.51 \pm 0.22$ & $10.49 \pm 0.24$ & $10.77 \pm 0.42$ \\
\hline M-CRT_THK (mm) & $0.63^{A} \pm 0.03$ & $0.68^{\mathrm{Bb}} \pm 0.03$ & $0.64^{\mathrm{a}} \pm 0.01$ \\
\hline M-CRT_A $\left(\mathrm{mm}^{2}\right)$ & $5.34^{\mathrm{A}} \pm 0.25$ & $5.71^{B} \pm 0.27$ & $5.60 \pm 0.25$ \\
\hline M-CRT_DEN $\left(\mathrm{mg} / \mathrm{mm}^{3}\right)$ & $1436.53^{A} \pm 10.26$ & $1471.53^{B} \pm 11.63$ & $1464.89 \pm 10.29$ \\
\hline M-CRT_CNT (mg/mm) & $7.67^{A} \pm 0.37$ & $8.39^{B} \pm 0.38$ & $8.20 \pm 0.34$ \\
\hline M-TOT_A $\left(\mathrm{mm}^{2}\right)$ & $8.79 \pm 0.40$ & $8.76 \pm 0.41$ & $8.87 \pm 0.28$ \\
\hline M-TOT_DEN (mg/mm³) & $957.84^{\mathrm{A}} \pm 47.27$ & $1034.18^{\mathrm{Bb}} \pm 33.35$ & $972.29^{\mathrm{a}} \pm 31.22$ \\
\hline M-TOT_CNT (mg/mm) & $8.49^{A} \pm 0.26$ & $9.06^{B} \pm 0.47$ & $8.96 \pm 0.42$ \\
\hline
\end{tabular}

SHO-RC - diet with recommended calcium dose - Ca content: $5000 \mathrm{mg} / \mathrm{kg}$ diet; SHO-LC and OVX-LC: low-calcium diet. (60\% recommended Ca dose - Ca content: $3000 \pm 0.1 \mathrm{mg} / \mathrm{kg}$ diet) SHO - sham-operated rats; OVX-ovariectomized rats

cortical thickness (D-CRT_THK, M-CRT_THK), cortical area (D-CRT_A, M-CRT_A), cortical density (D-CRT_DEN, M-CRT_DEN), cortical content (D-CRT_CNT, M-CRT_CNT), trabecular area (D-TRAB_A, M-TRAB_A), total area (D-TOT_A, M-TOT_A), trabecular density (D-TRAB_DEN M-TRAB_DEN), trabecular content (D-TRAB_CNT, M-TRAB_CNT), total density (D-TOT DEN M-TOT _ DEN), total content (D-TOT CNT, M-TOT CNT), polar strain index (D-RP-CM-W), as wel as periosteal (D-PERI CM-PERI C) and endosteal circumferences (D-ENDO C, M-ENDO C) where $\mathrm{D}$ - means distal part of bone; $\mathrm{M}$ - means middle part of bone.

$a, b$ - unlike capital letters mean statistically significant differences between SHO-RC and SHO- LC groups $(\mathrm{p}<0.05)$; A, B - unlike small letters mean statistically significant differences between SHO-LC and OVX-LC $(p<0.05)$

(-23.80\%). Ca hypoalimentation in SHO rats also lowered this parameter $(-13.04 \%, \mathrm{p} \leq 0.05)$. Analysis in the middle part of bone showed that ovariectomy significantly affected pQCT parameters, such as M-ENDO_C (+9.05\%), M-CRT_THK (-5.88\%), and M-TOT_DEN (-5.98\%). Additionally, calcium hypoalimentation in SHO rats influenced $(\mathrm{p} \leq 0.05)$ most parameters in this part of the bone.

Effect of diet enriched in fructan-containing sources on bone quality of OVX rats. Analysis of the results concerning the fructan sources (raw materials or fructan formulation) added to rat diet as its component, revealed significant differences in $\mathrm{Ca}$ femoral content, with the highest value obtained for OVX-LC-Y group (208.96 g/kg) (Tab. 1).

Feeding rats with low-calcium diets containing sorbets enriched with different fructan sources on bone quality in OVX rats, also showed significant enhancement of femoral calcium after 8 weeks of experiment (Tab. 2). The highest Ca level (25.13\% higher than in OVX-LC) was determined in the bones of animals fed the diet containing Jerusalem artichoke sorbet.

Analysis of the distal part of bone via pQCT showed that the values of distal trabecular density were higher, from 5\% (OVX-LC-F) to 13\% (OVX-LC-JA), compared with OVX$\mathrm{LC}$, but the differences among groups were not statistically significant. In addition, total density of this part of the bone was also slightly higher after adding fructan sources to the diet. The same tendency was shown when animals were fed with the diet enriched in fructan containing sorbets, with significant difference between the OVX-LC-YS vs. OVX-LC groups. Enhancement of D-TRAB_DEN from 6\% (OVXLC-JAS) to $24.9 \%$ (OVX-LC-YS) was also observed (Tab. 2).

The obtained results from the middle part of femur indicated significant changes in the endosteal circumferences, dependening on the diet composition. The addition of fructans (raw materials) to the diet led to the lowering $(\mathrm{p} \leq 0.05)$ of M-ENDO_C: $-8.00 \%$ in OVX-LC-JA, $-6.37 \%$ in OVX-LC-Y and $-6.52 \%$ in OVX-LC-F. Moreover, the value of M-TOTDEN was significantly enhanced for all raw materials.

The pQCT analysis also revealed that the presence offructanenriched sorbets in rat diet was associated with changes in the parameters of the middle part of the femur (Tab. 2). Animals fed with the diet containing sorbets (independently of the kind) had lower endosteal circumference in this area of the bone $(6.37 \%-10.37 \%$ in OVX-LC-JAS and OVX-LCYS, respectively). The values of M-CRT_THK (for OVXLC-YS and OVX-LC-FS) and M-TOT_DEN (for all groups fed diets containing sorbets) were significantly enhanced, compared to OVX-LC. Additionally, cortical thickness and total density were the highest in OVX-LC-FS $(+7.81 \%$ and $+7.05 \%$, respectively), compared with OVX-LC (Tab. 2 ).

There were 3 versions of PCA: the first included validation model groups, the second - all low-calcium groups, and the third - all experimental groups. When considering the first version (Fig. 1A, 1B), 2 reduced variables (eigenvalues 12.58 and 6.42) were obtained. The relevant differentiation was observed between SHO-RC and SHO-LC versus OVX-

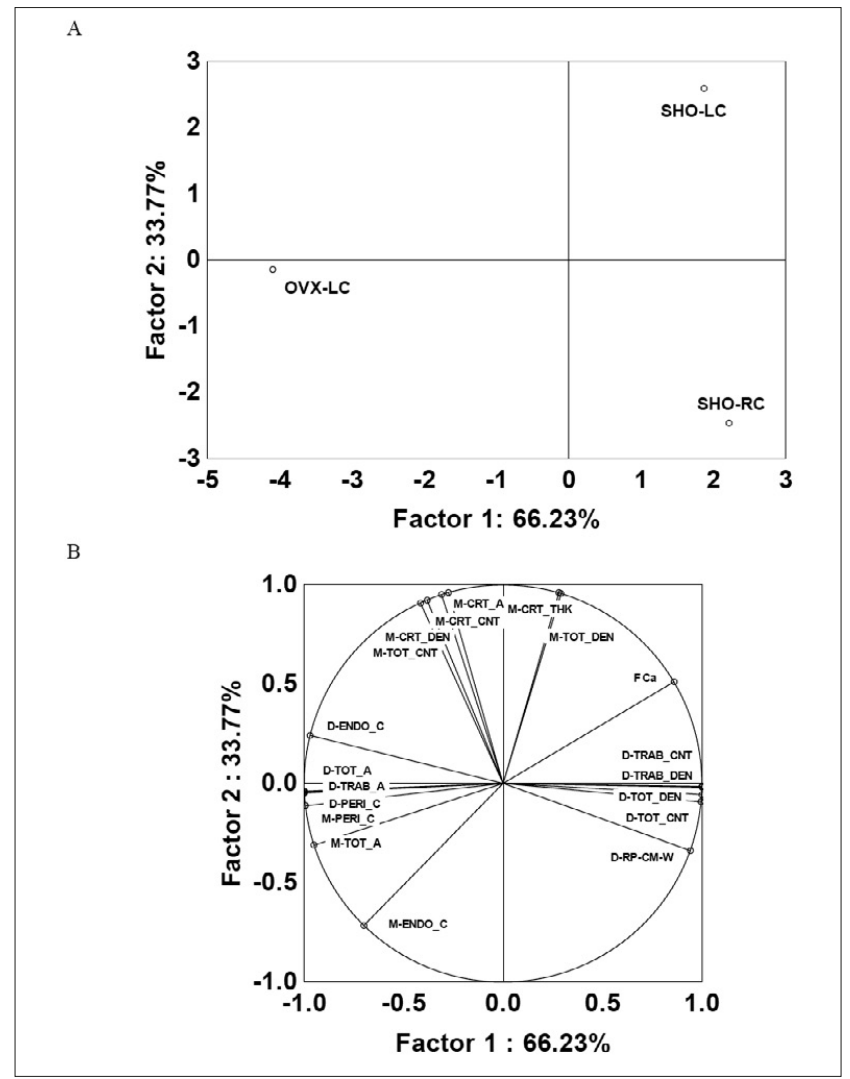

Figure 1. Principal component analysis (version 1 - groups of validation model) with distribution of: A - analyzed samples, B - analyzed parameters 
A
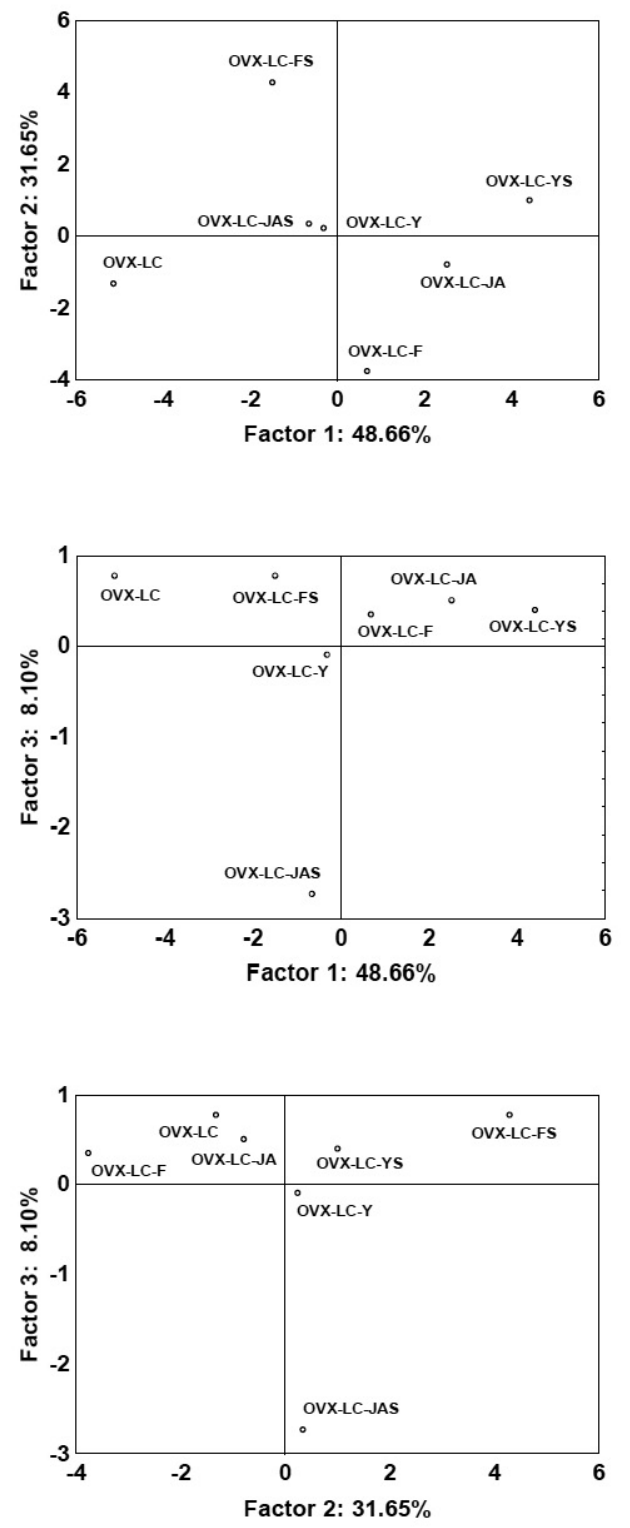

B
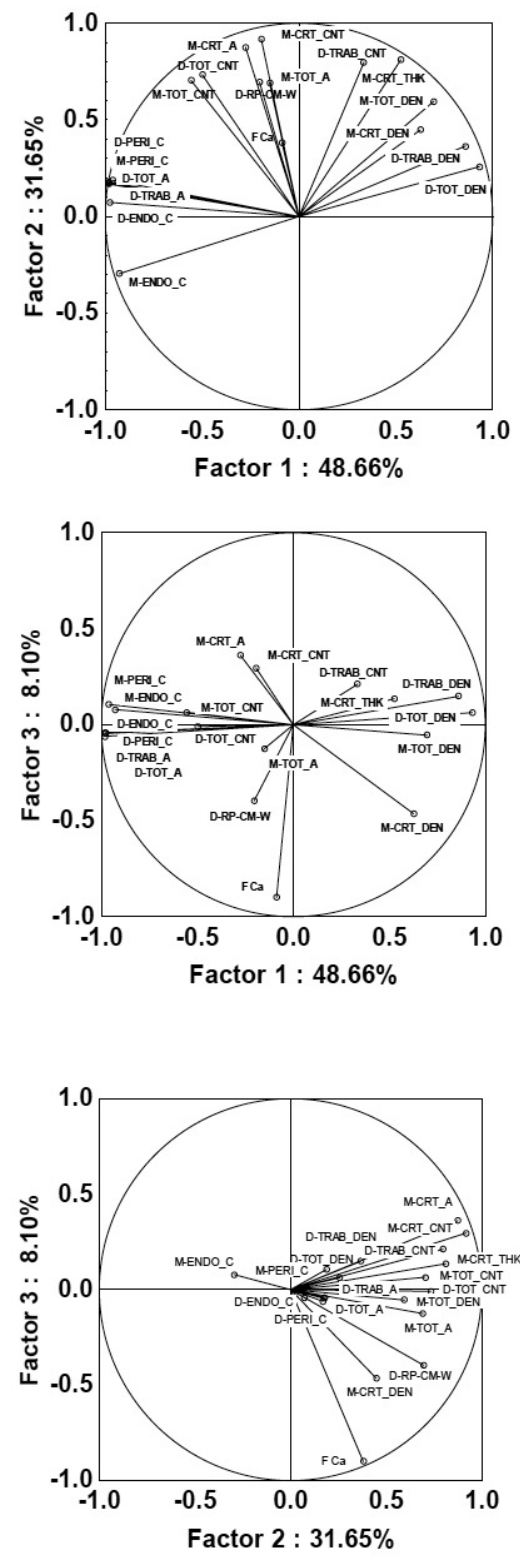

Figure 2. Principal component analysis (version 2 - without SHO groups) with distribution of: A - analyzed samples, B - analyzed parameters

LC rats (significant changes for both reduced variables). Simultaneously, among low-calcium groups (version 2 - Fig. $2 \mathrm{~A}, 2 \mathrm{~B})$, as a result of the reduction of 19 variables, 6 reduced (eigenvalues: 9.25, 6.01, 1.54, 1.09, 1.03, 0.09) variables explaining $100 \%$ variability were gained. Meanwhile, in the third version (including all experimental groups -validation as well as treatment groups, Fig. 3A, 3B), the reduction of 19 variables resulted in 8 reduced (eigenvalues: $8.44,5.02$, $3.61,1.10,0.55,0.16,0.09,0.02$ ) variables, explaining $100 \%$ variability. In these PCA versions, further analysis was focused only on the first 3 variables, explaining $88.4 \%$ and $89.9 \%$ variability, respectively. On the basis of the analysis of contributions of particular real variables in reduced variables, it was observed that LCD-YS changed, to the highest extent, parameters in the distal part of bone (factor $1-63 \%$ distal bone parameters), whereas LCD-FS - parameters in the middle part of bone (factor $2-65 \%$ middle bone parameters).

\section{DISCUSSION}

Bone loss resulting from estrogen deficiency has been widely studied in animals and humans. The ovariectomized rat is a useful model for mimicking estrogen withdrawal of women after menopause [5]. The progressive loss of bone matrix is similar to that in postmenopausal women with osteoporosis [17]. Animal models fed low Ca diets demonstrate a negative calcium balance and gross bone loss, while the combination of calcium deficiency and oophorectomy enhances overall bone loss [7]. The results of the presented study indicate that ovariectomy negatively affected $(\mathrm{p} \leq 0.05)$ femoral Ca content in rat femur (Suppl. Tab. 2). These findings are not surprising because it is well known that estrogen deficiency exhibits harmful effects on bone condition. Furthermore, the effects of calcium deficiency and ovariectomy are additive. If more calcium is repeatedly removed from bones than is replaced, 
A
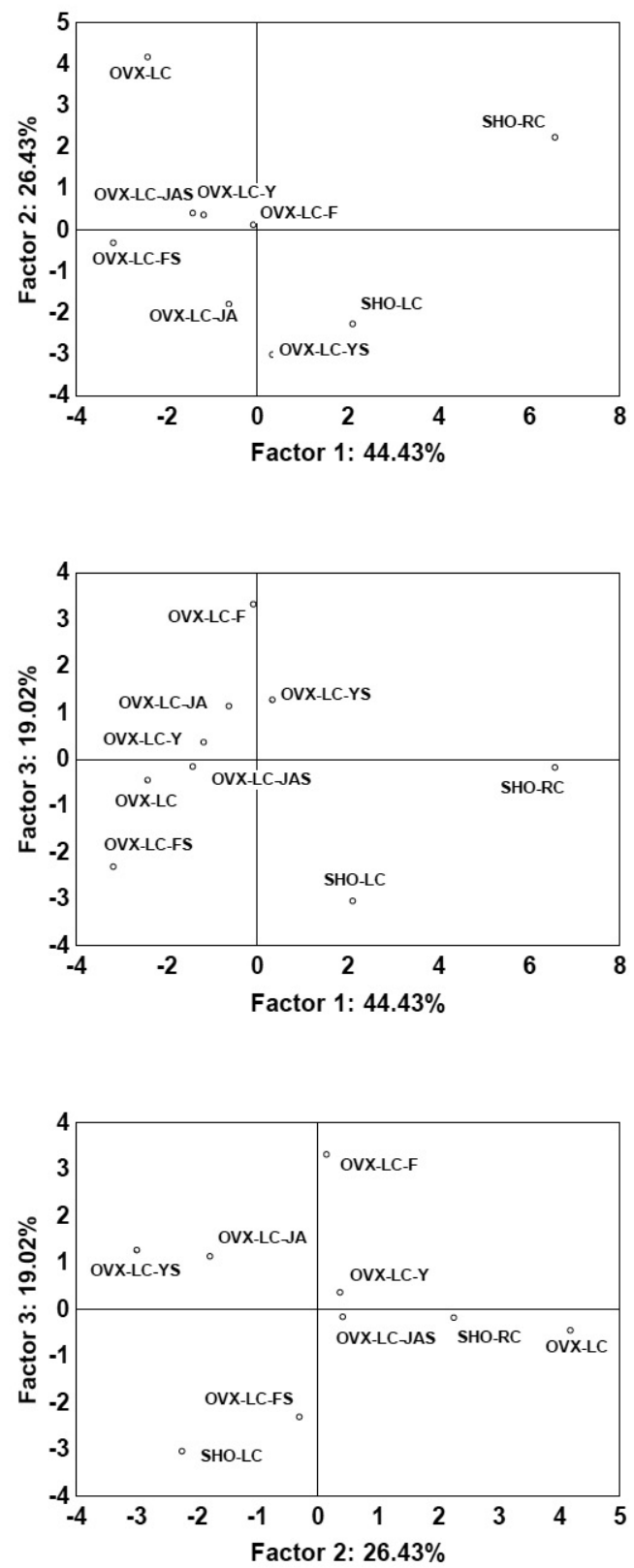

B
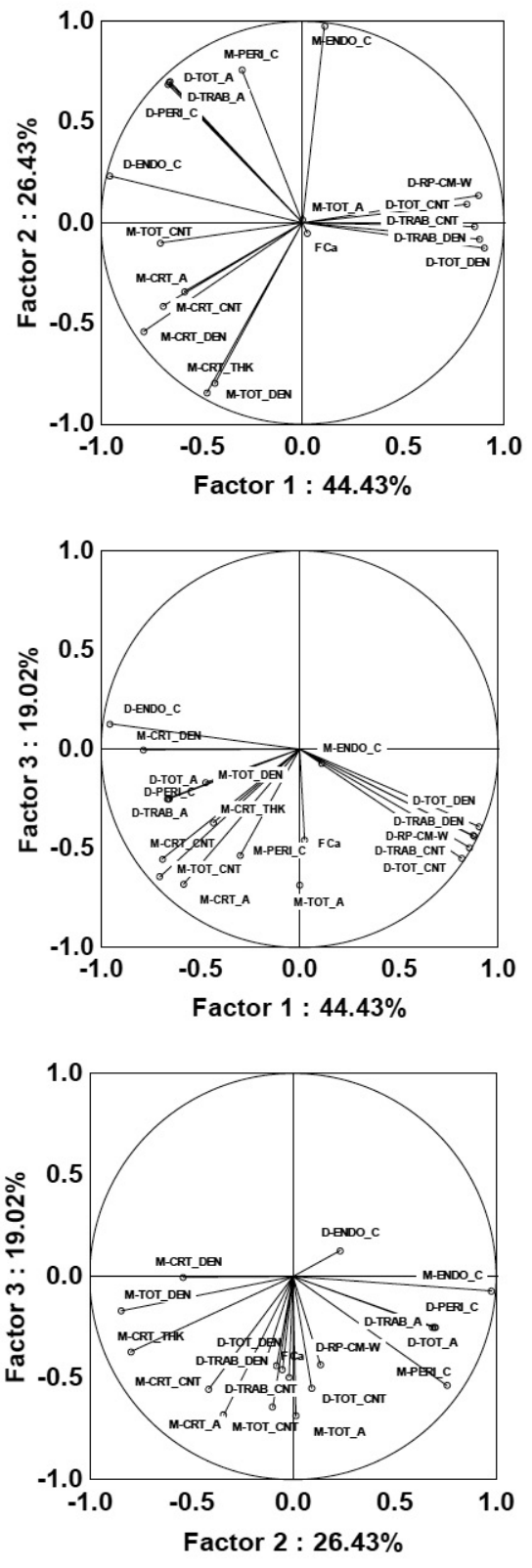

Figure 3. Principal component analysis (version 3 - all groups) with distribution of: A - analyzed samples, B - analyzed parameters

osteoporosis will eventually occur [20]. Similar observations were noted by Sookvanichsilp et al. [18], in young adult ovariectomized rats after an 8-weeks experimental period. The authors observed that ovariectomy caused a decrease in the growth of the long bones of rats, as well as their calcium content. Scholz-Ahrens et al. [19] also reported that femoral calcium in animals subjected to ovariectomy tended to be lower.

In general, the extent of ovariectomy-induced bone loss is dependent on many factors, including the skeletal site [4]. PQCT analyses of distal part of rat femora revealed that ovariectomy led to an increase in both periosteal and endosteal circumferences, compared with the SHO-LC group (Suppl. Tab. 2). OVX rats were also characterized by significantly lower trabecular content and trabecular density, as well as total mineral content and total bone density in this part of the femur. A dramatic decrease in D-RP-CM-W values was also observed under these conditions (ovariectomy, low-calcium diet). Significant changes in pQCT parameters: M-ENDO_C, M-CRT_THK and M-TOT_DEN were also shown in the middle part of bone.

Interestingly, in the current study, Ca content in femur was not markedly ( $\mathrm{p}>0.05)$ different between SHO groups fed normal and low-calcium diet (Suppl. Tab. 2). However, feeding SHO rats a calcium-deficient diet for 8 weeks led to negative changes in endosteal circumference measured in distal part of bone (analyzed via pQCT), whereas D-PERI_C remained almost the same (Suppl. Tab. 2). Additionally, there was a tendency to a decrease (by about 5\%) of trabecular density in the distal femora of $\mathrm{SHO}$ animals subjected to calcium 
hypoalimentation. In the presented study, significantly lower values of D-RP-CM-W parameter were shown in the group of sham-operated rats fed with the low-calcium diet. These experimental conditions also led to significant changes in most parameters in the middle part of bone, analyzed by pQCT (Suppl. Tab. 2).

Menopause is the most important risk factor for osteoporosis in adult women [21]. However, other risk factors involving lifestyle, such as low physical activity, insufficient vitamin D levels and a calcium-poor diet, are also common in modern society. For that reason, functional food products with the potential to prevent bone loss attract special attention. Few calcium absorption enhancers have been identified and the emerging evidence has shown that fructans could be an interesting dietary ingredients from this point of view [22]. They are being investigated for their potential to improve bone health, largely through their influence on mineral absorption and retention [5]. These beneficial effects of inulin-type fructans have been extensively studied in several experimental models, taking into consideration mineral metabolism and bone mineralization, as well as architecture [5, 23, 24, 25, 26]. According to Scholz-Ahrens and Schrezenmeir [27], the age of the animals and/or their physiological stage also affect the role that inulin plays in the metabolism of calcium; inulin type fructans, may be more effective when the animals have a higher demand for calcium, as in the rapidly growing age range or in estrogen deficiency. When regarding raw materials being a source of fructan, the results of Ca bone content depended on the kind of material chosen, with the highest value obtained for ovariectomized animals fed with a low-calcium diet, but enriched in yacon (Tab. 1). In turn, analysis of the results obtained in the current study concerning the sources of fructan, a component of strawberry sorbet added to the rat diet, revealed the highest $\mathrm{Ca}$ level in bones of rats fed a diet containing the product with Jerusalem artichoke (Tab. 2). Similar results were obtained by Topolska et al. [28], in an experiment using the model of growing female rats. The current results are in line with those obtained by Weisstaub et al. [5] who showed a positive effect of fructan (10 g Synergy per $100 \mathrm{~g}$ diet) on Ca content in the bone of ovariectomized rat. Scholz-Ahrens et al. [24] also showed that diet (with a recommended calcium dose) providing $10 \%$ oligofructose increased the levels of minerals in the femur of OVX animals. The effect of inulin on Ca metabolism was also studied by Weaver [29] as part of a metabolic balance study using 6-month-old ovariectomized rats. Bone formation rates increased $44 \%$ and bone resorption rates were completely suppressed (89\% increase in Ca retention).

When analyzing data from pQCT concerning the distal part of bone, a tendency was observed to enhance trabecular density, as well as total density in groups fed with fructan sources added to diet alone (Tab. 1). Similar observations were made in groups given diets enriched in sorbets with various fructan sources (Tab. 2). The addition of sorbet containing yacon to the diet significantly improved D-TOT_DEN, compared to the OVX-LC rat group. In the case of OVXLC-YS, as well as OVX-LC-FS, the value of D-TRAB_CNT was also higher. Despite their lack of statistical significance, these changes (even small) may contribute to a more stable trabecular network or locally higher bone mineralization with the effects on femoral stability. In turn, Scholz-Ahrens et al. [24] demonstrated that in aged ovariectomized rats, oligofructose added to the diet for 8 weeks prevented the loss of trabecular bone induced by estrogen deficiency; however, the effect became significant when the diet provided $1 \%$ of $\mathrm{Ca}$. According to Scholz-Ahrens et al. [19], the beneficial effect of oligofructose on bone mineral content and trabecular structure depends, inter alia, on its amount in the diet, and also on the duration of intervention. Moreover, it is known that bone remodeling is triggered by osteoblasts and osteoclasts [30]. The surface-to-volume of trabecular bone volume is nearly 10 times than of cortical bone, so its contribution to activation of bone metabolism is greater. It is therefore assumed that the decrease in bone density caused by calcium deficiency may occur in trabecular bone sooner than in cortical bone [20].

Feeding ovariectomized rats a diet enriched in fructan sources (as raw materials) led to marked reduction in the endosteal circumferences measured in the middle part of bone. Added to this, total density of this part was significantly higher (Tab. 1). As regards the action of fructan-enriched strawberry sorbets, lower endosteal circumference, higher cortical thickness and total density in the middle part of bone are to be mentioned, although the extent of these changes varied among groups (Tab. 2). The differences in the fructan action could be due to their degree of polymerization. It is assumed that oligofructose (with shorter DP) will be fermented more rapidly in the upper large intestine, whereas inulin (longer DP) will be fermented predominantly in the lower part, and a mixture of short-chain and long-chain inulin (Synergy) will be fermented all along the whole gut, and thus more effectively [27].

To find the dependence between nutrition and health, studies concerning the impact of various dietary components on the growth and/or condition of the organism are needed. The interpretation and conclusion from this kind of research is difficult, because of the necessity to evaluate many parameters (from one side differentiated, from the other - strongly correlated), that lead to an ambiguous image of various actions of diets/components. Thus, the implementation of a statistical tool that allows limitation of the number of variables and illustrates the gained results is crucial. A smaller number of dimensions makes it easier to find the differences between the analyzed samples. This is why Principal Component Analysis was applied, i.e. first version including groups of validation model, the second for all low-calcium groups, and the third, taking into account all experimental groups. As regards the first version (Fig. 1A, 1B), significant differences were observed between SHO-RC and SHO-LC only for reduced variable 2. Because of the fact that the components of this variable are parameters from the middle part of the femur (93\% reduced variable 2$)$, it may be concluded that Ca hypoalimentation affected the examined parameters in this part of bone to a higher extent than in the distal area. In turn, when regarding all lowcalcium groups (Fig. 2A, 2B), 6 reduced variables explaining $100 \%$ variability were obtained. Such as reduction indicates a strong association between the examined parameters. In the third version (including all experimental groups Fig. 3A, 3B), 8 reduced variables were obtained. Analysis of the PCA results (versions 2 and 3 ) indicated that the addition of fructans in the form of sorbet significantly influenced the examined parameters of bone condition, and rearranged the characteristics of the diet towards the sham-operated groups. On the basis of the analysis of contributions of particular real 
variables in reduced variables, it can be concluded that in the case of group consuming yacon as a component of sorbet, the effect concerned mostly the parameters of the distal part of bone. If the LCD-FS group is taken into account, the changes concerned the highest extent of parameters in the middle part of bone. The impact of LCD-JAS on bone quality was also shown; in this case, explicit differentiation (compared with other groups) was observed in the value of reduced variable 3 (factor 3), where femoral calcium content (FCa) played a dominant role $(53 \%)$.

It is well known that ovariectomy results in general changes in metabolism. The decrease in estrogen levels during the menopausal period leads to a loss of the protective effect of estrogen against oxidative stress and reactive oxygen species, followed by depletion in antioxidant enzymes in bones. Oxidative stress also suppresses bone formation by inhibiting osteoblast differentiation and decreasing the survival of these cells. The absence of estrogen reduces osteoblastic activity and stimulates osteoclastic activity, finally leading to the development of osteoporosis [31]. Topcuoglu et al. [32] demonstrated an elevation of plasma and tissue oxidative stress markers as a result of ovariectomy. In addition, hormone replacement therapies decreased oxidative stress markers in plasma and tissue of the OVX rats, suggesting a protecting effect of estrogens within the antioxidant defence systems [33]. In this context, the biological effects of fructanenriched sorbets on bone may be due to one or more of the bioactive compounds present in their composition. First, polyphenols are the most diffused and interesting bioactive compounds present in strawberry [34]. These compounds can protect bone health through reduction of oxidative stress because they act as antioxidants [35]. Strawberries are also a rich source of antioxidant vitamins, such as vitamin $\mathrm{C}$ and $\beta$-carotene.

The other point is that the results of recent studies indicate that fructans may have antioxidative potential [36]. In a study by Pasqualetti et al. [37], the total antioxidant capability of fructans, with different degrees of polymerization (DP 8-125) and molecular structures (linear or branched), was analyzed by the TEAC method. It was shown that fructans, resistant to thermal treatment and digestion, also increased their role as antioxidant molecules since their activity can take place in the colon, the part of the gastrointestinal tract that is not reached by other ROS scavengers, such as vitamins $\mathrm{C}$ and $\mathrm{E}$, which are absorbed in the first part of the human gut. Therefore, the reason for the more beneficial action of the diet containing strawberry sorbets enriched in fructan sources than the raw materials added to the diet alone, could be derived from other bioactive compounds of this kind of product, its specific physicochemical properties and the potential for enhancing fructan action. Further research on the combined effect of fructan action and antioxidant properties of strawberry are needed.

\section{CONCLUSION}

The presented study showed that diet containing inulin-type fructans improved bone quality. Different fructan sources had an effect on various femoral parameters. In detail, natural sources, i.e. Jerusalem artichoke (as a component of sorbet) or yacon (as a raw material) enhanced Ca content in femur. Diet containing sorbet enriched in yacon also had a positive impact on the total density and cortical thickness in the distal part of femur. Moreover, in the middle part of bone of animals fed diets containing sorbets enriched in each fructan source, total density was higher than in the low-calcium control group. Analysis of the PCA showed that the addition of fructans in the form of sorbet significantly influenced the examined parameters of bone condition. On the basis of the analysis of contributions of particular real variables in reduced variables, it can be concluded that in the case of the group consuming yacon as a component of sorbet, the effect was mostly on the parameters of the distal part of bone. If the group fed the diet containing sorbet enriched in fructan formulation is taken into account, the changes concerned (to the highest extent) parameters in the middle part of bone. Simultaneously, the impact of sorbet-enriched in Jerusalem artichoke on the quality of femur was also observed.

These findings suggest that a fructan-enriched diet is potentially useful for postmenopausal osteoporosis. It is important to determine an optimal dietary level of fructan with the long-term goal of developing a dietary strategy to prevent postmenopausal osteoporosis and related fragility fractures.

\section{Conflict of interest}

The authors declare they have no conflict of interest.

\section{Acknowledgements}

The study was founded by the National Science Centre Poland project, on the basis of Decision No. DEC-2011/01/B/ NZ9/03045.

\section{REFERENCES}

1. Elkomy MM, Elsaid FG. Anti-osteoporotic effect of medical herbs and calcium supplementation on ovariectomized rats. J Basic Appl Zool. $2015 ; 72: 81-88$

2. Kanis JA. WHO Technical Report. 2007; University of Sheffield, UK: 66.

3. Samia A, Hejar AR, Suriani I, Emilia ZA. An overview of osteoporosis and heath promotional strategies for community based osteoporosis prevention in Malaysia. IJPHCS. 2017; 4: 28-40.

4. Johnston BD, Ward WE. The Ovariectomized Rat as a Model for Studying Alveolar Bone Loss in Postmenopausal Women. Bio Med Res Int. 2015; Article ID 635023, 12 pages, http://dx.doi.org/10.1155/2015/635023.

5. Weisstaub AR, Abdala V, Gonzales ChMP, Zuleta Á, Zeni S. Polydextrose Enhances Calcium Absorption and Bone Retention in Ovariectomized Rats. Int J Food Sci. 2013; doi: 10.1155/2013/450794.

6. Kumssa, DB, Joy EJM, Ander EL, Watts MJ, Young SD, Walker S, Broadley MR. Dietary calcium and zinc deficiency risks are decreasing but remain prevalent. Sci Rep. 2015; 5: 10974; doi: 10.1038/srep10974.

7. Morris HA, O'Loughlin PD, Anderson PH. Experimental Evidence for the Effect of Calcium and Vitamin D on Bone. A Review. Nutrients. 2010; 2(9): 1026-1035.

8. Fonseca D, Ward WE. Daidzein together with high calcium preserve bone mass and biomechanical strength at multiple sites in ovariectomized mice. Bone. 2004; 35(2): 489-97.

9. Roberfroid MB. Inulin-type fructans: functional food ingredients. J Nutr. 2007; 137(11 Suppl): 2493S-2502S.

10. Hubert PA, Lee SG, Lee S-K, Chun OK. Dietary Polyphenols, Berries, and Age-Related Bone Loss: A Review Based on Human, Animal, and Cell Studies. Antioxidants. 2014; 3(1): 144-158. doi:10.3390/ antiox3010144.

11. Hannum, SM. Potential Impact of Strawberries on Human Health: A Review of the Science. Crit Rev Food Sci Nutr. 2004; 44: 117.dx.doi. org/10.1080/10408690490263756.

12. Giampieri F, Forbes-Hernandez TY, Gasparrini M, Alvarez-Suarez JM, Afrin S, Bompadre S, Quiles JL, Mezzetti B, Battino M. Strawberry as a health promoter: an evidence based review. Food Funct. 2015; 6(5): 1386-98. doi: 10.1039/c5fo00147a. 
13. Topolska K, Filipiak-Florkiewicz A, Florkiewicz A, Cieślik E. Fructan stability in strawberry sorbets in dependence on their source and the period of storage. Eur Food Res Technol. 2017; 243: 701-709.

14. Reeves PG, Nielsen FH, Fahey GC Jr. AIN-93 purified diets for laboratory rodents: final report of the American Institute of Nutrition ad hoc writing committee on the reformulation of the AIN-76A rodent diet. J Nutr. 1993; 123(11): 1939-1951.

15. PN-EN 15505:2008 Foodstuffs - Determination of trace elements Determination of sodium and magnesium by flame atomic absorption spectrometry (AAS) after microwave digestion. [In Polish]

16. PN-EN 13804:2003 Foodstuffs - Determination of elements and their chemical species - General considerations and specific requirements. [In Polish]

17. Hayatullina Z, Muhammad N, Mohamed N, Soelaiman IN. Virgin Coconut Oil Supplementation Prevents Bone Loss in Osteoporosis Rat Model. Evidence-based complementary and alternative medicine. eCAM. 2012; 237236. 10.1155/2012/237236.

18. Sookvanichsilp N, Tad-urai N, Lawtong P, Sittithumcharee G. Effects of Antiresorptive Drugs on Long Bone Growth, Body Weight Gain, and Serum Lipid Levels in Young Adult Ovariectomized Rats. J Pharm Sci. 2014; 41(4): 29-38.

19. Scholz-Ahrens KE, Adolphi B, Rochat F, Barclay DV, de Vrese M, Açil $\mathrm{Y}$, Schrezenmeir J. Effects of probiotics, prebiotics, and synbiotics on mineral metabolism in ovariectomized rats - impact of bacterial mass, intestinal absorptive area and reduction of bone turn-over. NFS J. 2016; 3: 41-50.

20. Kim Ch, Park D. The effect of restriction of dietary calcium on trabecular and cortical bone mineral density in the rats. J Exerc Nutr Biochem. 2013; 17(4): 123-131.

21. Najmutdinova DK, Nurmukhamedova LS, Alieva DA, Maksudova DS, Nosirova ZA Study of the Effects of the Age at Menopause and Duration of Menopause on Bone Mineral Density in Postmenopausal Women in Uzbekistan. Int J Biomed. 2016; 6(1): 38-40.

22. Coxam V. Inulin-type fructans and bone health: state of the art and perspectives in the management of osteoporosis. Br J Nutr. 2005; 93: S111-S123.

23. Takahara S, Morohashi T, Sano T, Ohta A, Yamada S, Sasa R. Fructooligosaccharide consumption enhances femoral bone volume and mineral concentrations in rats. J Nutr. 2000; 130: 1792-1795.

24. Scholz-Ahrens KE, Acxil Y, Schrezenmeir J. Effect of oligofructose or dietary calcium on repeated calcium and phosphorus balances, bone mineralization and trabecular structure in ovariectomized rats. $\mathrm{Br} \mathrm{J}$ Nutr. 2002; 88: 365-78.
25. Roberfroid M, Champ M, Gibson G. Nutritional and health benefits of inulin and oligofructose. Br J Nutr. 2002; 87 (Suppl 2): S139-311.

26. Zafar TA, Weaver CM, Zhao Y, Martin BR, Wastney ME. Nondigestible oligosaccharides increase calcium absorption and suppress bone resorption in ovariectomized rats. J Nutr. 2004; 134: 399-402.

27. Scholz-Ahrens KE, Schrezenmeir J. Inulin and oligofructose and mineral metabolism: the evidence from animal trials. J Nutr. 2007; 137(11 Suppl): 2513S-2523S.

28. Topolska K, Radzki RP, Filipiak-Florkiewicz A, Florkiewicz A, Leszczyńska T, Cieślik E. Fructan-Enriched Diet Increases Bone Quality in Female Growing Rats at Calcium Deficiency. Plant Foods Hum Nutr. 2018; https://doi.org/10.1007/s11130-018-0671-4.

29. Weaver CM Inulin, oligofructose and bone health: experimental approaches and mechanisms. Br J Nutr. 2005; 93 (Suppl 1): S99-103.

30. Tanaka Y, Nakayamada S, Okada Y. Osteoblasts and osteoclasts in bone remodeling and inflammation. Curr Drug Targets Inflamm Allergy. 2005; 4: 325-328.

31. Abujazia MA, Muhammad N, Shuid AN, Soelaiman IN. The Effects of Virgin Coconut Oil on Bone Oxidative Status in Ovariectomized Rat. Evidence-Based Complementary and Alternative Medicine. 2012; Article ID 525079, 6 pages, https://doi.org/10.1155/2012/525079.

32. Topcuoglu A, Uzun H, Balci H, Karakus M, Coban I, Altug T, et al. Effects of estrogens on oxidative protein damage in plasma and tissues in ovariectomized rats. Clin Invest Med. 2009; 32: E133-43.

33. Albano E, Mottaran E, Occhino G, Reale E, Vidali M. Review article: role of oxidative stress in the progression of non-alcoholic steatosis. Aliment Pharmacol Ther. 2005; 22: 71-3. doi: 10.1111/j.1365-2036.2005.02601.x.

34. Giampieri F, Tulipani S, Alvarez-Suarez JM, Quiles JL, Mezzetti B, Battino M. The strawberry: composition, nutritional quality, and impact on human health. Nutrition. 2012; 28(1): 9-19 doi: 10.1016/j. nut.2011.08.009.

35. Dudarić L, Fužinac-Smojver A, Muhvić D, Giacometti J. The role of polyphenols on bone metabolism in osteoporosis. Food Res Int. 2015; 77: 290-298.

36. Franco-Robles E, Ramírez-Emiliano J, López MG. Agave fructans and oligofructose decrease oxidative stress in brain regions involved in learning and memory of overweight mice. Nat Prod Res. 2018. doi: 10.1080/14786419.2017.1423297.

37. Pasqualetti V, Altomar, A, Guarino MPL, Locato V, Cocca S, Cimini S, Palma R, Alloni R, De Gara L, Cicala M. Antioxidant Activity of Inulin and Its Role in the Prevention of Human Colonic Muscle Cell Impairment Induced by Lipopolysaccharide Mucosal Exposure, PLOS ONE 2014 9(5): e98031. doi.org/10.1371/journal.pone.0098031.

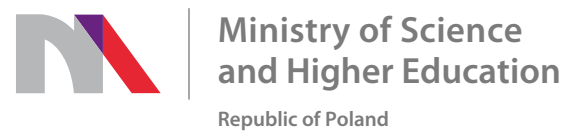

Generation of the DOI (Digital Object Identifier) - task financed under the agreement No. 618/P-DUN/2019 by the Minister of Science and Higher Education 